\title{
The Effect of Personality on Accent Acquisition: Case Study of Effat University Students
}

\begin{abstract}
Accent acquisition is the landmark of fluency in a second language. Different factors have been debated over to be the most important in the process, such as: age and exposure (Oyama 1976). Personality is an additional factor that has been researched comparatively recently and has been proven to be effective (Robinson et al. 1994). The current study investigated personality as an effective factor in the process of accent acquisition. Participants in this study were forty-eight native speakers of Arabic who study and live in KSA; a minority of Effat university students who speak English with a native-like American accent. Their remarkable American accent raised the question of the relationship between the type of personality and accent perfection. The accuracy of their American accent was measured by the means of: (1) semi-structured interviews, (2) reading a text in English, and (3) spontaneous talk on a topic of their choice. The researcher was assisted in the interviews by a native speaker of American English (a PhD in Creative Writing) to evaluate the participants' accent. Following to that, three Native speakers of American English (all university professors) were asked to assist in the second and third phases of evaluation process; respectively reading and spontaneous talk. The results indicated that personality is an effective predictor of native accent acquisition. Age and level of exposure were not as strong predictors in the case of this study.
\end{abstract}

Keywords: accent acquisition, personality, second language acquisition, Arabic speakers, American accent, bilinguals, fluency

\section{Introduction}

Social, cultural, and cognitive variables affect second language acquisition (Gardner 1985; Bialystok 1991; Cummins 1991). Specifically, accent acquisition has long been regarded as the mark of integration into the mind of the native speakers of this language and the final part of the equation. Acquiring the accent of a certain language is the proof that the process of understanding another culture is complete. This is when the speaker is indistinguishable from the group, and can partake in their identity. Literature on the accent acquisition issue is controversially divided in a number of directions in which a group of linguists adopt a certain factor to be the most important in the accent acquisition process. These factors are: age, exposure, motivation, learning environment and personality.

This was the departure point for this research; that is to understand what could be the reason behind the ability of the cases in study to speak American English with a native-like American accent. Based on the researcher's initial interaction with the students, it has been ascertained that a 
few students had limited experience living or studying in an English speaking country; the majority of these students had no experience studying or living outside of Saudia Arabia. This eliminated the element of immersion to a natural environment of the language in early age as a common denominator. Additionally, the participants reported to have started learning English in varied types of elementary schools (public, private and international) which has, as well, eliminated the factor of learning environment. The questions remained: why were all these young Saudi women pronouncing English with American accents, despite of their different social and educational backgrounds? Was it something psychological, instinctual rather than cerebral causing some students to not only speak English fluently, but without a trace of Arabic as a base language?

\subsection{Effat University in the Saudi Culture}

The social and academic cultures of Effat University are important to mention to introduce for the role they play in shaping and affecting the personalities of its students. Effat University is an expensive private English-based school located in Jeddah, KSA that welcomes students from different nationalities which is not a common thing in KSA where governmental schools do not accept non-Saudi students. Another distinctive thing about Effat University is that even though students are all females, it is a mixed environment of male and female faculty and staff members who come from a wide range of different countries. This situation has resulted in a dynamic academic environment of different cultures, languages, and colors that promotes research into different aspects of second language acquisition especially from a cultural perspective.

Theorists of culture and personality school that has emerged in the first half of the $20^{\text {th }}$ century as a reaction against the 19th century social evolution and diffusion argue that the type of socialization one has creates personality patterns. It might shape a person's emotions, thoughts, behaviors, cultural values and norms. Similar to the interactive relation between culture and personality, culture and language also share an interactive relation. This can be summed up in Byram's definition of language as "shared beliefs, values and behaviors of a social group" (Byram 2008: 60), and Kramsch's (2002) description of language as a tool that is not only used to exchange information, but also as a symbolic system that has the power to create and shape symbolic realities, such as values, perceptions, identities through discourse.

Departing from this interactive relation between culture and personality on one hand, and personality and language on the other hand, the researcher wanted to examine how personalities of the students who choose to join a university with such a unique dynamic culture in KSA are shaped and how this can be related to their acquisition of native-like English American accent. Specifically, the researcher attempted to answer the question: what is the relationship between personal dispositions and accent procurements? Specifically, the study delves into how temperament is instrumental in affecting fluency and pronunciation by the means of investigating American accent acquisition in distinguishable minority of young Saudi women who speak English with indistinguishable American Accent. 


\section{Literature on factors affecting second language acquisition}

Literature on the acquisition of a second language in general, and its accent in specific has shown a wide range of variable factors that play a role in the process. Among these are the agreed-upon factors such as: age, exposure and the closeness between the learner's native language and the acquired one. On the other hand, more recent research has shown other factors that may be of more controversial nature, such as: attitudes toward the second language and the target language group, openness to a culture that is relatively new to the learner, individual differences, teaching methods, design of the learning environment, motivation, the conditions of learning the second language (Spolsky 1989; Berman 1990), interest in learning the second language as a function of the attitude of the specific learner, learning situation, instrumental and integrative motivation (Abu Rabia 1999; Gardner 1985) and the main interest of this research, personality.

\subsection{Age and exposure}

Accent Acquisition is a component of a second language acquisition process that shows how far the learner is comfortable with the acquired language. It is widely believed that there is a critical age after which the learner is not going to be able to acquire the native accent (Pallier et al. 1997). This age is when a learner can still learn the new phonetic system of the new language and integrate it into the phonetic system s/he already has. Lennenberg (1967) claimed that this critical age is a neurological age period that ends near teenage years. Oyama (1976) argued in favor of the existence of a defining age point for acquiring a native accent of a second language after investigating children acquiring second languages in natural environments, where the language is obtained through immersion. Generally, it has been proven that children are better speakers than adults who have been sharing the same environment. Scovel (1981) argues in favor of the importance of age over any other factor in accent acquisition. He theorizes that the age factor is neurological in nature; that acquiring an accent involves the intervention of certain nerves in the human body. Learners who start learning a second language after the age of twelve will never be able to acquire its flawless native accent regardless of the amount of exposure they might get. Long (1990) seconds this argument and adds that exposure to the second language that leads to a native accent acquisition has to occur before the age of six and not later than the age of twelve.

On the other hand, there are linguists who hold that an accent can be acquired at any time in life depending on the level of exposure to the second language and the contact with the target group people. Neufeld (1979) has found that Canadian native English speakers who started learning French as adults succeeded in acquiring the native French accent. This supports the claim that acquiring the accent of the second language is possible even after the presumed critical age period. Additionally, Bongaerts et al. reported in (1995) that native English accent could be attained by the Dutch learners who were educated in formal instructional setting after the age of twelve. The level of their accent accuracy was compared to that of the native speakers control group, also their accent was perceived as native accent by native speakers. Studies on Dutch people learning French 
as a second language (Bongaerts et al. 1997) and studies on late learning of Dutch as a second language (Bongaerts et al. 2000) were all supporting replications of Bongaerts et al. 1995).

Anecdotal research has shown a case of an Anglophone who became a German teacher at the university level and was a subject of Moyer's (1999) investigation. This individual was mistaken by raters for a native speaker of German; he was reported to have started learning German at the age of twenty two and was largely self-taught. The one characteristic he had and distinguished him from his peer subjects of the same study was a strong desire to sound German.

Much of the recent work in this regard conducted by Flege and others (1997) has highlighted the importance of environmental factors on acquiring the native accent of a second language. Among these is exposure; as in the period of time spent in a country hosting for the target language (Riney and Flege 1998). Also, time spent in the company of native speakers (Flege et al. 1997) was found to be a major determinant of quality of second language accent. However, Klein (1993) argues that extensive and continuous exposure to the second language is an essential factor, but not enough in attaining native second language accent. High motivation to learn the language and strong desire to sound like a native speaker combined with good linguistic aptitude can lead to acquiring a native accent even after the agreed upon critical age period.

\subsection{Motivation}

Motivation is another highly related factor to the acquisition of a second language. It is highly accepted that the stronger the learner's desire to sound like a native speaker, the more s/he is likely to sound like one (Pursel and Suter 1980). On the other hand and in his study of sixty Italian immigrants to the USA, Oyama (1976) found that motivation is of no effect on accent acquisition and that it is irrelevant to the phonological system/s a speaker has. In this study, only one variable was found to predict the quality of the second language accent acquisition which is the age of arrival to the USA.

However, other researchers (Gardner and Lambert 1972) agree that positive attitudes to the language and the target language group cause strong motivation to learn the second language and to communicate with the hosting community of the acquired language. Also, Suter (1976) found negative correlations between students' attitudes to integrate with American society and their ability to pronounce words like native speakers. He tested sixty-one Arab, Japanese, and Persian students. The variables that predicted native accent acquisition were similar phonological systems of the native language and English, the importance of accent acquisition as reported by the participants, and the importance of speaking English as natives in workplaces and schools. The last two variables showed negative correlations with accent acquisition.

\subsection{The present study}

This study presents an investigation of native-like American English accent acquisition among Arab students of a Saudi private university. The purpose is to recognize how far personality, in terms of traits and preferences, is effective as a factor in the process of accent acquisition. The age 
of learning English as a second language, motivation and exposure to native speakers of American English were only checked as variables, but not thoroughly investigated as factors in the process of accent acquisition.

The importance of this study lies in the gap it is expected to fill in the research field of accent acquisition. Specifically, the results will better portray personality as a main factor in the process of language acquisition, in general, and accent acquisition, in particular. Consequently, the study can help teachers of English as a second language to achieve better results with learners, particularly Arabic native speakers.

\section{Methodology}

\subsection{Participants}

Fifty-seven students were invited as participants, only forty-eight were found to have American accents that were accurate enough to investigate as native accent. The participants are native speakers of Arabic who are Saudi young women. At the time of the study, they were between the ages of eighteen and twenty-two. The case studies in question are a distinguishable minority of students at Effat University who speak English with flawless American accent. The researcher and a native speaker American English held the interviews, then two additional judges (total of three) evaluated the participants' accents in both reading and spontaneous talk. The judges were all native speakers of American English, two females, and one male, $\mathrm{PhD}$ holders (one in American Literature, one in Creative Writing, and one in Sociology) and professors at Effat University.

\subsection{Measures}

Participants were tested individually in three different methods: (1) semi-structured interviews, (2) oral reading of a short text and (3) spontaneous talk. The interviews were meant to evaluate the sense of distinctiveness with each student's life, their sense of both English and Arabic and how this is related to culture. The students were first interviewed by a native speaker of American English, who is a $\mathrm{PhD}$ in Creative Writing, to primarily evaluate the accuracy of their accents and to have an overall idea of where they stand from Western culture, in general and American culture, in specific. Immediately after, the students were interviewed by the researcher, in Arabic, to evaluate their sense of Arabic language and culture. The selected forty-eight students were asked to read a text that was about half a page from a children's story book, composed of short and easy sentences in English. The level of the reading was deliberately chosen to be remarkably easy in order to avoid any possibility of unknown vocabulary and syntax that might have impeded the reading fluency. The text contained English sounds considered difficult for native Arabic speakers; either because they do not exist in Arabic or because they are pronounced differently. Examples of these were: $/ p /, / v /$, flapped $/ t /, / r /, / d /$ etc. Finally, the participants were asked to pick up a topic on their own and spontaneously talk about it for a minute at their usual speed. 


\subsection{Procedure}

Participants were tested in their free time, especially during students' activity time for the interviews parts. The testing procedure went as follows:

1. Semi-structured interviews conducted in English by a PhD native speaker of American English and followed immediately by an interview in Arabic conducted by the researcher. The purpose of these two interviews was to evaluate the participants' sense of both English and Arabic languages as well as their perception of Western culture vs. Arabic culture. The two interviewers agreed previously on the structure of the interview, however none of them attended the other's sessions with the participants.

2. A reading of a short text that was carried out in separate sessions depending on each student's free time. They were given the reading and asked to read it a few times so as to avoid any reading-error effect. Then, the participants read out loud and were tape-recorded. ${ }^{1}$

3. The reading taping was followed by a taping of the one minute spontaneous talk. For the second and third steps, participants were allowed to self-tape in private if desired to avoid embarrassment. Some have done that for the spontaneous talk only, others for both the reading and the spontaneous talk. The recorded reading text and spontaneous talk were submitted to the three judges for accent evaluation. The scale was $1=$ very heavy Arabic accent, $2=$ heavy Arabic accent, 3= moderate Arabic accent, $4=$ near native American accent, and 5= native American accent. Each judge evaluated the tapes individually and without sharing ideas with the others. Judges decided to disregard reading and/or linguistic errors and to only focus on the accent of pronunciation. The tapes were randomly delivered to the judges so that no relation can be created between the two tasks, each of which was evaluated on separate sheets.

4. After revising the results of the previous three steps, the researcher recalled the participants for a follow-up interview. This interview was designed to have a better understanding of the participants' personalities and what they might have in common. Questions of this interview were adopted from the Myers-Briggs Type Indicator (MBTI) which is an online free instrument to measure personality types. The point was to develop a perspective on the participants' preferences in specific decision-making situations to see if they have a certain type of personality in common which might have better chances in accent acquisition of a second language even if learnt after the critical age and without exposure to the hosting country environment.

\section{Results}

At the time of this study, the participants were all Effat University Students; the youngest of which was eighteen and the oldest was twenty-two years of age. Table (1) below shows the statistics of the independent variables that the participants answered at the very beginning of the first interview. The purpose was to draw a picture that includes the participant's age, the age when they

\footnotetext{
1 A script of the short reading is given in Appendix 3.
} 
started learning English, the importance of having American accent to them, the level of exposure they have on daily basis via media and internet and finally if they are friends/acquaintances with American native speakers (the third and fourth variables were graded by the participants on a scale of $1-$ very little to $5=$ excessively.

Table (1) Descriptive Statistics of the Independent Variables

\begin{tabular}{|l|l|l|l|}
\hline Independent Variables & Mean & SD & No. \\
\hline Chronological age (years) & 21.6 & 6.27 & 48 \\
\hline Age on starting to learn English & 14.79 & 5.38 & 48 \\
\hline Importance ascribed to American accent & 4.97 & 1.20 & 48 \\
\hline Level of Exposure to American English & 3.70 & 0.93 & 48 \\
\hline $\begin{array}{l}\text { Number of American friends/ } \\
\text { acquaintances }\end{array}$ & 2.92 & 3.21 & 48 \\
\hline
\end{tabular}

\subsection{Interviews results ${ }^{2}$}

The first interviews were semi-structured in design. The participants were first asked close-ended questions to set the independent variables as stated in the above section. That was followed by open-ended questions to have a better understanding of their linguistic vs. cultural sense. These questions covered issues such as the languages they would say they are fluent in, their background of English and their intuitive linguistic choice when they express themselves in different situations. This interview also covered their cultural sense in terms of their preferences with respect to music, movies and books. Additionally, the participants were asked about their future plans concerning the leaving or staying in Saudia Arabia. Finally, they were asked to express the first thing that comes to their mind when they hear certain words (Foreigner and American in the English interview and Arab and Saudi in the Arabic interview).

Only one out of forty-eight interviewees mentioned Arabic (second to English) as a language that she is fluent in, while the other forty-seven did not even consider mentioning Arabic as a language they are fluent in, even though the Arabic interviews showed that if they want, they can use vernacular Arabic in a perfect sense. The interviews have shown that as far as the background of English is concerned, only three of the interviewees had lived as children for short periods (one to four years) in an English speaking country (two in the UK and one in the US); ten of the participants received their elementary education in private schools, eight in international schools, twen-

2 A script of the full interview questions is given in Appendix 1. 
ty-seven in public schools. All forty-eight of the participants admitted that responding in English is their first intuition in different self-expression situations such as, anger, hurt, and laughter.

In regard to the questions that targeted their cultural preferences, all forty-eight of the participants agreed that they only listen to English music, watch American movies and read books written in English. When they were asked in the Arabic interview if they would listen to Arabic music, read Arabic books, and/or watch Arabic drama, only four of them responded positively while the others completely declined this, even as a possibility. Thirty-seven of the participants had tentative plans of leaving Saudia Arabia after graduation with no intention to come back, while five of them planned to leave to study abroad with the possibility to come back and six of them were fine with the idea of staying in Saudia Arabia. Different responses were given to the question of how they feel about the words Arab/Saudi, Foreigner/American. The results showed that the words Arab/Saudi were not synonymous to them as Arab was a manifesto of how they see themselves and they had no shame in showing this identity. Whereas, they saw the word Saudi as a symbol of everything they long to change in their country. Similarly, foreigner/American did not mean the same thing for them since they saw foreigner to mean someone who is not Saudi including other Arab nationalities; twelve thought of music, movies and other types of entertainment, fourteen thought of green areas and parks and twenty-two answered Trump when the word American was mentioned.

\subsection{Reading and spontaneous talk judges' evaluation}

The three designated judges were asked to give ratings (score out of 5) for the participants' recorded readings and spontaneous talks. The ratings of the first judge was $x=4.62$ on reading, and $\mathrm{x}=4.58$ on the spontaneous talk. The second judge's rating was $\mathrm{x}=4.66$ on reading, and $\mathrm{x}=4.64$ on spontaneous talk. The third judge's rating was $\mathrm{x}=4.44$ on reading, and $\mathrm{x}=4.40$. the total mean rating of the three judges on reading was $\mathrm{x}=4.57$, and on spontaneous talk $\mathrm{x}=5.45$. The descriptive statistics of these ratings are given in table (2). The statistical analysis of the judges' evaluations showed no significant differences. All participants followed the instructions of reading out loud the given passage three times, however, forty five out of the forty eight participants exceeded the one minute limit of spontaneous talk on a free topic.

Table 2. Means and Standard Deviations of the Three Judges' Ratings of Participants on Reading Spontaneous Talk ( $\mathrm{N}=48)$

\begin{tabular}{|l|l|l|}
\hline Variables & Mean & SD \\
\hline Reading $1^{*}$ & 4.62 & 0.88 \\
Reading 2* & 4.66 & 0.82 \\
Reading $3^{*}$ & 4.44 & 0.81 \\
Total & 4.57 & 0.68 \\
& & \\
\hline
\end{tabular}




\begin{tabular}{|l|l|l|}
\hline Variables & Mean & SD \\
\hline Spontaneous Talk 1* & 4.58 & 0.93 \\
Spontaneous Talk 2* & 4.64 & 0.85 \\
Spontaneous Talk 3* & 4.40 & 0.76 \\
Total & 4.54 & 0.73 \\
& & \\
\hline
\end{tabular}

${ }^{*} 1,2$ and 3 are the evaluations of three judges. Maximum Score is (5.00)

\subsection{Follow-up interviews results ${ }^{3}$}

The follow-up interviews aimed to deeply investigate the personality-based preferences of the case studies to find the common traits they had and helped them to acquire a perfect American accent. To achieve this goal, the questions in the follow-up interviews were adopted from the MBTI which is an instrument to sort for personality types based on preferences, but does not measure ability, or character. Participants were asked to elaborate on their answer after each of the questions that attempted to cover their preferences in:

- Favorite world: Do they prefer to focus on the outer world or on their own inner world? Extraversion (E) or Introversion (I).

- Information: Do they prefer to focus on the basic information they take in or do they prefer to interpret and add meaning? Sensing (S) or Intuition (N).

- Decisions: When making decisions, do they prefer to first look at logic and consistency or first look at the people and special circumstances? Thinking (T) or Feeling (F).

- Structure: In dealing with the outside world, do they prefer to get things decided or do they prefer to stay open to new information and options? Judging (J) or Perceiving (P).

Participants were elaborate on their answer after each of the above questions. Results of the follow up interviews showed: (1) only three of forty-eight interviewees would prefer to spend their time in extroverts' activities; (2) all of the participants agreed that they prefer individual effort as far as studying is involved, furthermore, they have also stated that they have been working on their English skills individually not in classes; (3) for decisions, all of the participants responded that all of their decisions are made after thinking and considering rationale, and never in compensation with the society or family values; (4) four of the participants admitted that they prefer to get things decided, while the other forty-four were clear that they prefer to stay open to new information and options, however, all agreed that either way, they would hardly accept the social norms with regard to important decisions. According to MBTI, the type of personality in common among the participants is: INTP (Logical. Conceptual. Analytical. Objective. Detached. Critical. Ingenious. Complex. Intellectual curious. Loves ideas. Pursues understanding. Questioning. Adaptable. Independent).

3 A script of the full follow-up interview questions is given in Appendix 2. 


\section{Discussion}

Results of the first interviews and the evaluations of the three judges supported the researcher's intuition that the students in question speak English fluently with a native-like American accent. The independent variables tested at the beginning of the interviews showed that: firstly, the immersion factor was overruled since only $6 \%$ of the case studies had a background of living in the US or the UK as children, even these few cases spent in these countries short periods of their very early childhood. Secondly, the existence of critical age period in order for the native accent of the second language to be acquired was supported as all of the participants, except for one, started learning English in the early age of being less than four and not more than six. Thus, even when a learner is not in the natural environment of the language, it was clear that the younger the learner, the greater the chance is to acquire a second language native accent which seconds age as a strong predictor of accent acquisition. These results accord with Scovel (1981) and Long (1990) who argued for a theory of an early critical age in life for one to be able to acquire a native accent.

Thirdly, even though exposure as a factor in accent acquisition was remotely tested in this study as an independent variable, answers of the participants have shown no significant relationship between level of exposure and accent acquisition. The results indicate that participants who reported a high level of exposure to American English via internet and media and/or actual engagement in situations where they were obligated to speak American English with other American English native speakers scored no better on native accent measures than those who reported little or remarkably less exposure to American English. However, exposure remains a controversial factor in the literature; Thompson (1991) argued that exposure did not affect acquisition of the native accent and Klein (1993) supported that massive and continuous exposure to second language did not affect the learner's accent, while Berman (1990) found that the level of exposure did affect the level of accent acquisition. It is worth mentioning that the current study did not have enough room to deeply investigate exposure as a factor in accent acquisition.

Results of the interviews also showed that the participants shared several personality and cultural preferences such as their choice to express themselves in English over Arabic in different emotive, academic and other daily life situations. additionally, they have all chosen to associate themselves with American culture regarding music, movies, readings, attire and other forms of self-expression and entertainment. It is worth mentioning that all the interviewed students reported to be friends with other students who are amongst the case studies.

The above mentioned common cultural and personal preferences reported by the participants were in favor to the initial hypothesis that a certain personality type, specifically in the environment of the study, is a highly important factor in language learning and particularly in accent acquisition. Thus, the follow-up interviews were carried out using a specific personality scale (MBTI) to draw on the participants' personalities. The results supported the initial hypothesis that the students shared a certain personality type which seems to have made accent acquisition easier to them compared to other students with similar educational backgrounds. Despite minor differences in their responses to the MBTI questions, the overall results indicated all of the case studies 
to be INTP (Logical. Conceptual. Analytical. Objective. Detached. Critical. Ingenious. Complex. Intellectual curious. Loves ideas. Pursues understanding. Questioning. Adaptable. Independent).

The personality type resulted to be common amongst the students (INTP) can be explained within the preferences areas examined namely: case studies are introverted, intuitive, thinking and judging learners. Introverted learners are reported to tend to learn better in individual independent situations that involve more of ideas and concepts than theories and premises. Their strengths are their ability to concentrate on a certain task in hand as well as their self-sufficiency. The students, in study, admitted that they mostly need the urge to process ideas in their minds before speaking them out in a class room or a social gathering which is a great help, in their view, to avoid linguistic risk-taking in conversations. Technology, media and internet are their most enjoyable learning tools.

Being intuitive learners can be explained that such learners learn more effectively from flashes of insight, using their imagination, and grasping the general concepts rather than all the details. Their strengths are their ability to guess from the context, structuring their own training, conceptualizing and model building. However, they can be hindered by inaccuracy which may explain the syntactic and semantic mistakes traced in the interviews and in the spontaneous talks.

The thinking learners learn better and more effectively from impersonal circumstances and logical consequences. Their strengths are in their ability to analyze and their self-discipline. However, the case studies have shown a high level of anxiety with respect to their performance in English languages. They have reported that they strongly need to be fluent in English and to sound like Americans in order for them to be relaxed in classes; they have even associated their self-esteem to their achievement especially in English performance.

The participants of the study have been indicated as judging learners who learn more efficiently by reflection, analysis and processes that involve conclusion. These learners always want the job to get done, and in this specific case, the target of the case studies is to speak fluent American English with no trace of Arabic being the base language. This may also explain the fact that those specific students prefer to spend their time on campus together in smaller groups and that they expressed that dealing with other students make them uncomfortable and suffer from linguistic ambiguity that they cannot tolerate.

\section{Conclusion and recommendations}

Thus, the results of the study support the researcher's hypothesis that in addition to well-established factors that affect language acquisition and shape the level of accent fluency, such as age and exposure, personality is a key factor in determining the learner's success in accent acquisition. The study answers the research question that a relationship between personal dispositions and accent procurements can be traced in learners who choose to associate themselves with the culture of the learned language. Such learners, as in the cases of the study, have a better chance in acquiring the native accent of this language. In addition to their cultural and social choices, the case studies of this study have shown to have similar personal preferences in learning styles 
which may be helpful to be taken in consideration, especially in situations of teaching English as a second language to native speakers of Arabic. Even though no perspective is ever completely accurate and reliable, the more perspectives teachers have, the more clearly they can understand learners and be able to help them.

In conclusion, personality traits can have a direct and indirect impact on learning and their role as predictors of our students' learning should not be discounted. However, their impact cannot be considered in isolation, as divorced from motivation and the cognitive and cognitive-oriented factors identified at the outset of my discussion. Teachers are often prompted by course administrators or educational consultants to take into account our students' learning styles and multiple intelligences; but maybe more effort should go into equipping teachers and school staff in general (a) with a better grasp of how students' personality type may impact their learning and (b) with effective strategies to best adapt our teaching to learner psychological needs.

All the important findings of this research study should be communicated to teachers who can directly implement teaching strategies and/or to researchers who can do further research on any topic that will bring about an improvement in teaching strategies for English as a second Language.This will help change the students' attitudes toward learning the English language.

For further research, I suggest using larger samples with different testing conditions, specifically, to test accents of male and female students from different Arab countries who started learning English at different ages and under different social, educational, and emotional conditions. Such research may reveal whether or not the native accent of a second language is authentic and achievable in a regular classroom if certain personalities were pursued and technically supported amongst students. Testing accent acquisition under different conditions will uncover the possible implications of this important concept.

\section{References}

Abu-Rabia, Salim. 1999. Attitudes and Psycholinguistic Aspects of First Language Maintenance among Russian-Jewish Immigrants in Israel. Educational Psychology, 19, 133-148.

Berman, Ruth. 1990. A Dispute over the Truth: Between First and Second Language. Head HaolpanHakhadasha 59, 27-33.

Bialystok, Ellen. 1991. Metalinguistic Dimensions of Bilingual Language Proficiency. In Ellen Bialystok (ed.), Language Processing in Bilingual Children, 113-140. Cambridge, UK: Cambridge University Press.

Bongaerts, Theo, Brigitte Planken and Erick Schils. 1995. Can Late Starters Attain a Native Accent in a Foreign Language: A Test of the Critical Period Hypothesis. In David M. Singleton and Zsolt Lengyel (eds.), The Age Factor in Second Language Acquisition, 30-50. Clevedon: Multilingual Matters LTD.

Bongaerts, Theo, Chantal Van Summeren, Brigitte Planken and Erick Schils. 1997. Age and Ultimate Attainment in the Pronunciation of a Foreign Language. Studies in Second Language Acquisition 19, 447-465. 
Bongaerts, Theo, Susan Mennen and Frans Van den Slik. 2000. Authenticity of Pronunciation in Naturalistic Second Language Acquisition: The Case of very Advanced Late Learners of Dutch as a Second Language. Studia Linguistica 54, 298-308.

Byram, Michael. 2008. From Foreign Language Education to Education for Intercultural Citizenship. Clevedon: Multilingual Matters.

Cummins, James. 1991. Interdependence of first-and second language proficiency. In Ellen Bialystok (ed.), Language processing in bilingual children,70-89. Cambridge, U.K.: Cambridge University Press.

Flege, James E., Elaina M. Frieda and Takeshi Nozawa. 1997. Amount of Native Language (L1) Use Affects the Pronunciation of an L2. Journal of Phonetics 25, 169-186.

Gardner, Robert C. 1985. Social Psychology and Second Language Learning: The Role of Attitudes and Motivation. London: Edward Arnold.

Gardner, Robert C. and Wallace E. Lambert. 1972. Attitudes and Motivation in Second-Language Learning. Rowley, Mass: Newbury House Publishers.

Klein, Elaine C. 1993. Toward Second Language Acquisition. Toronto: Kluwer Academic Publishers. Kramsch, Claire. 2009. Discourse, the Symbolic Dimension of Intercultural Competence. In Adelheid $\mathrm{Hu}$ and Michael Byram (eds.), Interkulturelle Kompetenz und Fremdsprachliches Lernen. 107-124. Tübingen: Gunter Narr.

Lennenberg, Eric. 1967. Biological Foundations of Language. NY: Wiley Publishers.

Long, Michael. 1990. Maturational Constraints on Language Development. Studies in Second Language Acquisition 12, 251-285.

Moyer, Alene. 1999. Ultimate Attainment in L2 Phonology: The Critical Factors of Age, Motivation and Instruction. Studies in Second Language Acquisition, 21, 81-108.

Neufeld, Gerald G. 1979. Towards a Theory of Language Learning Ability. Language Learning 29, 227-241.

Oyama, Susan. 1976. A Sensitive Period for the Acquisition of a Nonnative Phonological System. Journal of Psycholinguistic Research 5, 261-283.

Pallier, Christophe, Laura Bosch and Sebastian Galle. 1997. A Limit on Behavioral Plasticity in Speech Perception. Cognition 64, 9-17.

Pursel, Edward T. and Richard W. Suter. 1980. Predictors of Pronunciation Accuracy: A Reexamination. Language Learning 30, 271-287.

Riney, Timothy and James E. Flege. 1998. Changes over Time in Global Foreign Accent and Liquid Identifiability and Accuracy. Studies in Second Language Acquisition 20, 213-244.

Robinson, David, Norman Gabriel, Olga Katchan. 1994. Personality and Second Language Learning. Personality and Individual Differences 16(1), 143-157.

Scovel, Tom. 1981. The Recognition of Foreign Accents in English and its Implications for Psycholinguistic Theories of Language Acquisition. Proceeding of the Fifth International Association of Applied Linguistics. New York. 389-401. 
Spolsky, Bernard. 1989. Conditions for Second Language Learning. Oxford: Oxford University Press.

Suter, Richard W. 1980. Predictors of Pronunciation Accuracy. Language Learning 26, 233-253.

Thompson, Irene. 1991. Foreign Accents Revisited: The English Pronunciation of Russian Immigrants. Language Learning 41, 177-204.

\section{Web 1 - MBTI}

http://www.myersbriggs.org/my-mbti-personality-type/mbti-basics/home.htm?bhcp=1 (30 November 2017) 


\section{Appendix 1}

A Setting independent variables questions

$1 \quad$ How old are you?

2 What age were you when you started learning English?

a. Less than 6 years.

b. Between $6-12$ years.

c. More than 12 years.

3 On a scale from 1 to five state how important it is for you to speak English with a native-like American accent; 1 being very little and 5 being excessively.

4 On a scale from 1 to five state how frequently you are exposed to American English spoken by native speakers; 1 being very little and 5 being excessively.

5 How many family members, friends and/or acquaintances who are native speakers of American English do you have?

a. Less than 5 people.

b. Between 5 - 10 people.

c. More than 10 people.

\section{B Open-ended questions of the first interview}

1 What languages would you say you are fluent in, and to what degree?

2 What is the general educational level of your parents?

$3 \quad$ How did you learn English? Try to give a portray of the whole background?

4 Which language are you comfortable using when you are in an emotional situation or when you want to express yourself best?

5 What language do you prefer to read and write in?

6 What is the language of your favorite music and entertainment shows and why?

7 Do you watch Arabic drama or listen to Arabic music?

8 Do you have future plans for your future after graduation regarding staying in or leaving KSA?

9 What would be the first image/thing that comes to your mind when you hear the words Arab and Saudi?

10 What would be the first image/thing that comes to your mind when you hear the words foreigner and American? 


\section{Appendix 2}

\section{Questions of follow-up interviews}

1. Your best spent time is:

a. With family and friend enjoying the outer world.

b. With your own self focusing on your inner world.

- Elaborate

2 Your way of handling information is to:

a. Take in and focus on basic information given to you.

b. Interpret and add meaning to information given to you.

- $\quad$ Elaborate

3 Your decisions are made on the basis of:

a. Logic and consistency.

b. People and circumstances.

- Elaborate

4 When dealing with the outside world, do you prefer to:

a. Get things decided.

b. Stay open to options.

- $\quad$ Elaborate

\section{Appendix 3}

Reading a book is fun. Books make you smarter. They also make you a better reader. John loves to read books. He reads books on sunny days. He reads books on cloudy days, and he reads books on rainy days. John has read many books. He read his first book in second grade. His teachers were impressed. John was a good student. He had the highest grades in class. John learned a lot by reading books. He learned new words. He learned new verbs. He learned new adjectives. John reads every day. He has learned about the world. He has learned about history. He has learned about animals. He has learned about people. John loves to learn. He learns something new every day. John has many books. He has large bookshelves. They are full of books. John collects books. He has bought books at bookstores. John wants to read every book in the world. 